[Letter]

\title{
Methanol Synthesis from Carbon Dioxide and Hydrogen via Formic Ester
}

\author{
Yoshitada Sakaiya, Li Fan *, Kaoru Fujimoto \\ Department of Applied Chemistry, School of Engineering, \\ The University of Tokyo, Hongo, Bunkyo-ku, Tokyo 113-8656, Japan
}

(Received May 21, 1998)

A new route of methanol synthesis, at $473 \mathrm{~K}$ and $30 \mathrm{bar}$, from carbon dioxide and hydrogen through formic ester was reported, by using active carbon supported palladium catalyst and coexisting weak base. This one-pot reaction consisted of 3 steps: (1) formic acid synthesis from $\mathrm{CO}_{2}$ and $\mathrm{H}_{2}$, (2) esterification of formic acid by ethanol to ethyl formate, (3) hydrogenolysis of ethyl formate to methanol and ethanol, the rate-determining step. Longer reaction time favored methanol synthesis and high $\mathrm{CO}_{2}$ conversion.

\section{Introduction}

As carbon dioxide is the main source of green house effect, it is very important to fix it or to change it to other chemicals. Because of its low reactivity, it is difficult to synthesize oxygenates such as methanol and methyl formate from carbon dioxide. Generally high temperature and high pressure are necessary for oxygenate synthesis from hydrogenation of carbon dioxide. Jessop et al. reported that supercritical-phase $\mathrm{CO}_{2}$ can be hydrogenated to formic acid by a coordinated ruthenium catalyst, with the aid of amine and/or further additive ${ }^{1)}$. On the other hand, methanol synthesis form $\mathrm{CO}$ and $\mathrm{H}_{2}$ via methyl formate has been widely studied, where carbonylation of methanol, hydrogenation of methyl formate were included ${ }^{2)-4)}$. But in this reaction, $\mathrm{CO}_{2}$ and $\mathrm{H}_{2} \mathrm{O}$ were poisonous to the catalyst and must be completely removed from syngas. BNL method is an effective synthesis route for low-temperature methanol synthesis from syngas where the catalyst is derived from coexisting acetate, alcohol and sodium hydrid ${ }^{5}$. Similarly $\mathrm{CO}_{2}$ and $\mathrm{H}_{2} \mathrm{O}$ can not be included in the reactant gas.

Based on the literature above, we propose a new reaction route, which is hydrogenation of carbon dioxide to methanol via formic ester. More concretely, it is composed of three steps as shown below: (1) carbon dioxide is hydrogenated to formic acid, (2) immediately it reacts with ethanol, accompanying

\footnotetext{
* To whom correspondence should be addressed.
} 
solvent to form ethyl formate, (3) then methanol and ethanol are produced by further hydrogenolysis of ethyl formate. Thermodynamically, methanol synthesis from $\mathrm{CO}_{2}$ and $\mathrm{H}_{2}$ is favored at low temperature, indicating the feasibility of this new route. In fact, step (1) should be easily realized, as formate was the intermediate of water-gas shift reaction. Step (2) is well known to be a very fast reaction. Step (3) is industrially operated at $453 \mathrm{~K}$ and 30 bar on some solid catalysts ${ }^{3)}$. Theoretically, this new route seems not to be very difficult, if suitable catalyst is employed. We aim to accomplish these three reactions in one reactor. The supported Pd catalyst on active carbon showed highest activity among active carbon supported metal catalysts, while the weak base as additives (carbonate etc.) coexisted. The reaction conditions were investigated in use of these catalysts and additives. It is expected that methanol or formic ester can be formed from carbon dioxide at mild reaction conditions.

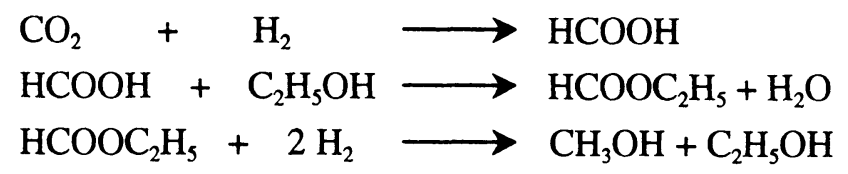

\section{Experimental}

Typical batch reactor was employed in the reaction. Loading of $\mathrm{Pd}$ for the $\mathrm{Pd} /$ active carbon (A.C.) catalyst (N.E.CHEMCAT) in this study was $5 \mathrm{wt} \%$. Before reaction, catalyst was reduced in $\mathrm{H}_{2}$ gas at $673 \mathrm{~K}$ under atmospheric pressure. In the experiment the Pd / A.C. catalyst and additive was put into the reactor, and ethanol as a solvent was poured in, and the pressurized mixture gas of $\mathrm{H}_{2}(75 \%)$ and $\mathrm{CO}_{2}(25 \%)$ was introduced, then the reaction took place at the desired temperature. The standard reaction conditions were as follows: catalyst weight $=0.20 \mathrm{~g}$; additive $\left(\mathrm{K}_{2} \mathrm{CO}_{3}\right)$ weight $=0.10 \mathrm{~g}$; solvent quantity=172 mmol; mixture gas quantity=63 mmol $\left(\mathrm{CO}_{2}\right), 21 \mathrm{mmol}\left(\mathrm{H}_{2}\right)$; initial pressure $=30$ bar.

All products were confirmed on GC-MS (Shimadzu GCMS 1600) and analyzed by gas chromatography (Shimadzu GC-8A).

\section{Results and Discussion}

The results in Table 1 show the effect of the base addition. The catalyst used was Pd / A.C. catalyst. If the basic additive was not used, diethyl ether was produced, by the dehydration of two molecules of ethanol. Ethyl formate and methanol were not produced at this condition (at $473 \mathrm{~K}$, for $2 \mathrm{~h}$ ), without the base addition. At any case, $\mathrm{CO}$ selectivity was high, due to the reverse water-gas shift reaction of $\mathrm{CO}_{2}$ and $\mathrm{H}_{2}$. It is well known $\mathrm{CO}_{2}$ could hardly adsorb onto the supported $\mathrm{Pd}$ and Pt catalysts, without the aid of the support or additive ${ }^{6,7)}$. It is considered that carbon dioxide could easily adsorb onto the catalyst by the aid of base; and the target reaction was possible to proceed.

It is clearly demonstrated in Table 1 that, with the addition of weak base, ethyl formate formed 
remarkably, indicating that reactions (1) and (2) proceeded smoothly. It should be noted here that the methanol did not form, as the reaction temperature or the reaction time was not enough, which will be discussed below.

Table 1 The effect of coexisted base

\begin{tabular}{|c|c|c|c|c|c|c|}
\hline Additive & $\begin{array}{c}\mathrm{CO}_{2} \text { conv. } \\
(\%)\end{array}$ & $\begin{array}{c}\mathrm{CO} \text { sel. } \\
(\%)\end{array}$ & $\begin{array}{c}\mathrm{CH}_{4} \text { sel. } \\
(\%)\end{array}$ & $\begin{array}{c}\text { C2+ sel. } \\
(\%)\end{array}$ & $\begin{array}{c}\text { ethyl formate } \\
\text { sel. (\%) }\end{array}$ & $\begin{array}{c}\text { ethyl ether } \\
\text { yield (mmol) }\end{array}$ \\
\hline None & 0.42 & 44 & 16 & 40 & 0 & 1.8 \\
\hline $\mathrm{Li}_{2} \mathrm{CO}_{3}$ & 1.2 & 29 & 65 & 0 & 6 & 0.02 \\
\hline $\mathrm{K}_{2} \mathrm{CO}_{3}$ & 2.5 & 74 & 2 & 0 & 24 & 0 \\
\hline $\mathrm{Na}_{2} \mathrm{CO}_{3}$ & 1.2 & 36 & 4 & 0 & 60 & 0 \\
\hline $\mathrm{Cs}_{2} \mathrm{CO}_{3}$ & 1.8 & 50 & 10 & 0 & 40 & 0 \\
\hline $\mathrm{CH}_{3} \mathrm{COOK}$ & 2.2 & 50 & 30 & 0 & 20 & 0 \\
\hline $\mathrm{CH}_{3} \mathrm{COONa}$ & 1.9 & 54 & 11 & 0 & 35 & 0 \\
\hline $\mathrm{HCOOK}$ & 4.7 & 79 & 1 & 0 & 20 & 0 \\
\hline
\end{tabular}

Catalyst: $5 \mathrm{wt} \% \mathrm{Pd} / \mathrm{A} . \mathrm{C}$.; solvent: ethanol; reaction time: $2 \mathrm{~h}$; temperature: $473 \mathrm{~K}$.

These bases could be supported onto $\mathrm{Pd} / \mathrm{A}$. C. catalyst and used for the reaction. But in this case, the yield of ethyl formate and/or methanol was lower than that of the directly-added case. The results in Fig. 1 and Fig. 2 exhibit the effect of the reaction temperature and reaction time in the reaction with $\mathrm{Pd} /$ A.C. and $\mathrm{K}_{2} \mathrm{CO}_{3}$. $\mathrm{CO}$ was produced in large amount, and it indicated that reverse water-gas shift reaction happened meanwhile. The selectivity of the produced ethyl formate was increased as the reaction

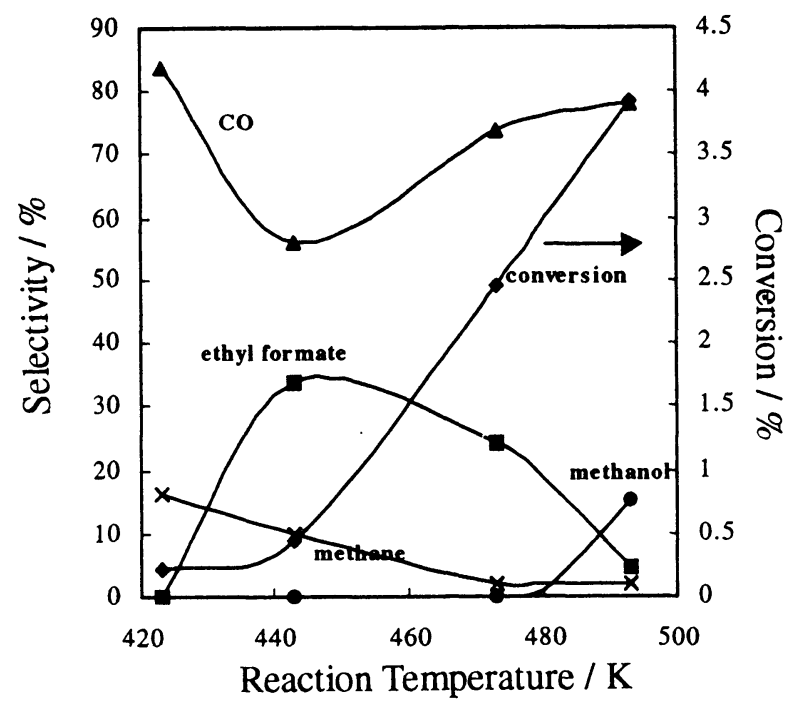

Reaction conditions: reaction time $2 \mathrm{~h}$; catalyst $5 \mathrm{wt} \% \mathrm{Pd} / \mathrm{A} . \mathrm{C}$.; additive $\mathrm{K}_{2} \mathrm{CO}_{3}$; solvent ethanol Fig. 1 The Effect of Reaction Temperature

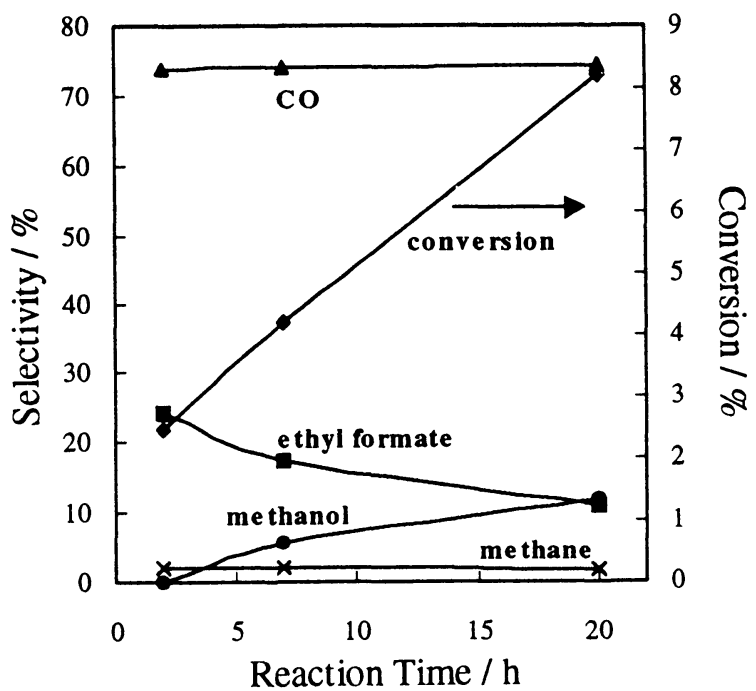

Reaction conditions: reaction temp. $473 \mathrm{~K}$; catalyst $5 \mathrm{wt} \% \mathrm{Pd} / \mathrm{A} . \mathrm{C}$.; additive $\mathrm{K}_{2} \mathrm{CO}_{3}$; solvent ethanol Fig.2 The Effect of Reaction Time

temperature rose up to $443 \mathrm{~K}$, and it was decreased while the temperature was higher. Methanol was not produced if reaction temperature was below $473 \mathrm{~K}$, in the case of $2 \mathrm{~h}$ reaction. But as exhibited in Fig. 1, 
when the reaction temperature was higher than $473 \mathrm{~K}$, methanol selectivity increased obviously, even if the reaction time was only $2 \mathrm{~h}$.

On the other hand, if reaction time became longer than $2 \mathrm{~h}$, methanol could be produced at $473 \mathrm{~K}$, as shown in Fig. 2. It is estimated that even if at low temperature such as $473 \mathrm{~K}$ or lower, methanol can be still synthesized in high selectivity if the reaction time was prolonged. It is clear that in Fig. 2 where $\mathrm{Pd} / \mathrm{A}$.C. and $\mathrm{K}_{2} \mathrm{CO}_{3}$ was used, $\mathrm{CO}_{2}$ conversion was enhanced remarkably while the reaction time increased. Meanwhile $\mathrm{CO}$ selectivity was nearly the same and methanol selectivity was increased gradually, with the correspondent decrease of ethyl formate. These results suggested that methanol was produced from carbon dioxide and hydrogen via ethyl formate. And it seemed that the hydrogenolysis of ethyl formate was the rate-determination step in this series reaction. It was easy to form ethyl formate, slower to convert ethyl formate to methanol. Longer reaction time or slightly higher reaction temperature was favorable to reaction (3), methanol synthesis from hydrogenolysis of formic ester. Also, a large amount of coexisting ethanol was not favorable to reaction (3), due to the equilibrium limitation. As the overall reaction of these three steps is exothermic, rather high temperature should lead to the low formation rate of methanol. As both reactions (1) and (3) are molecule-reducing reactions, high reaction pressure would be helpful to the overall reaction.

\section{References}

1) Jessop, P. G., Hsiao, Y., Ikariya, T., Noyori, R., J. Am. Chem. Soc., 118, 344(1996).

2) Palekar, V. M., Jung, H., Tierney, J. W., Wender, I., Appl. Catal., 102, 13(1993).

3) Kim, K. M., Woo, H. C., Lee, K. H., Lee, J. S., Kim, Y. G., Appl. Catal., 83, 15(1992).

4) Gormley, R. J., Rao, V. U. S., Soong, Y., Micheli, E., Appl. Catal., 87, 81(1992).

5) Haggin, J., Chem. \& Eng. News, 1986, 21, Aug. 4.

6) Fan, L., Fujimoto, K., J. Catal., , 172, 238(1997).

7) Shao, C., Fan, L., Fujimoto, K., Iwasawa, Y., Appl. Catal., 128, L1(1995).

\section{Keywords}

Carbon dioxide, Hydrogenation, Hydrogenolysis, Methanol, Ethyl formate, Palladium catalyst 